\title{
Revisiting Spatiotemporal Changes in Global Urban Expansion during 1995 to 2015
}

\author{
Yang Zhang, ${ }^{1}$ Huiying Wang, ${ }^{2}$ Peng Xie $\mathbb{D},{ }^{3}$ Yingxue Rao $\left(\mathbb{D},{ }^{4}\right.$ and Qingsong He ${ }^{5}$ \\ ${ }^{1}$ College of Urban Economics and Public Administration, Capital University of Economics and Business, Beijing 100070, China \\ ${ }^{2}$ School of Public Administration, University of International Business and Economics, Beijing 100029, China \\ ${ }^{3}$ School of Resource and Environmental Science, Wuhan University, 129 Luoyu Road, Wuhan 430079, Hubei Province, China \\ ${ }^{4}$ College of Public Administration, South-Central University for Nationality, Wuhan 430074, China \\ ${ }^{5}$ College of Public Administration, Huazhong University of Science \& Technology, 1037 Luoyu Road, Wuhan 430074, \\ Hubei Province, China
}

Correspondence should be addressed to Peng Xie; xiepenggis@163.com and Yingxue Rao; raoyingxue_ryx@163.com

Received 7 February 2020; Revised 14 April 2020; Accepted 29 April 2020; Published 29 May 2020

Guest Editor: Mohammad Swapan

Copyright (c) 2020 Yang Zhang et al. This is an open access article distributed under the Creative Commons Attribution License, which permits unrestricted use, distribution, and reproduction in any medium, provided the original work is properly cited.

This study used global land-use data interpreted from remote sensing images to quantitatively analyze the spatial and temporal changes in global urban expansion over the past 20 years, as well as the source, rate of expansion, and urban growth patterns of newly added urban land (NAUL) around the world. Some main conclusions included the following. (1) Globally, NAUL was mainly derived from agriculture, grassland, and forest. These three types of land use contributed $68.93 \%, 10.10 \%$, and $9.76 \%$, respectively, to the land sources for NAUL. (2) Eight countries/regions (CRs)_India, Pakistan, Nigeria, Bangladesh, Philippines, Ethiopia, Egypt, and Vietnam-had significant potential for future urban growth and were designated as the "Emerging Urban Growth G8." Also, Africa will continue to lead global urbanization after Asia. (3) Global urban expansion was still in a typical stage of edge expansion. Urban expansion in Oceania was the most aggregated, whereas in Asia, it was the most diffuse. (4) Apart from African CRs, the urban expansion rate in most CRs was higher than the population urbanization rate, so urbanization does not pose a significant threat to global food security. In addition, for CR with NAUL $>1,000 \mathrm{~km}^{2}$, the level of economic development had a positive effect compact urban development. This study mapped large-scale urban expansion using unified data, a unified definition of urban boundaries, and over a unified time span.

\section{Introduction}

Cities are land surface areas where human activities are the most concentrated and land-use intensity is the highest [1-3]. With continuous urbanization, a large proportion of the rural population has moved into cities. According to statistics and estimates by the United Nations, only $30 \%$ of the world's population lived in cities in 1950. However, by $2050,68 \%$ of the population is expected to be living in urban areas. The rapid increase in urban populations has given rise to huge demands for urban lands, resulting in the continuous expansion of urban lands [4,5]. Study of the spatiotemporal processes of urban land growth is not only an important research topic but also a basic component of research on global environmental change [6-8]. The relationships between urban expansion and other phenomena/ processes have been the focus of different bodies of research, e.g., the relationships between urbanization and economy [9], health $[10,11]$, the natural environment [12-15], and climate [16-20].

Urban expansion encroaches on the land around the city [21]. The conversion of valuable farmland around cities is the most common form of land urbanization [22, 23]. The conversion of forestland into urban built-up land in many regions of the world has also been widely reported [24, 25]. In addition, Las Vegas, Dubai, and other cities located within deserts have met the needs of urban development through sand fixation and land reclamation. Hong Kong, Singapore 
[26], and other coastal cities have greatly expanded their urban space through land reclamation projects. Ulaanbaatar, Mongolia's capital, has supplemented new construction land through the conversion of grassland on the outskirts of the city [27]. All of these processes make up a wide variety of sources of built-up urban land around the world. On the other hand, there are significant differences in urban expansion rates in different CRs. Urbanization in developing CRs started later but developed more rapidly than in developed CRs during the same period. From 1990 to 2015, urban populations in developing CRs tripled while land expansion increased by an average of 3.5 times. During the same period, the urban population in developed CRs increased by 1.2 times while land expansion increased by 1.8 times. Most future urban population growth will occur in developing CRs in Asia and Africa [28], as well as other developing country clusters [29]. China's urbanization process has been particularly striking and is even considered to be one of the two key factors shaping the new setup of the world in the 21st century [30]. Different urban expansion rates have different effects on the urban morphology evolution. Developing CRs are still upgrading their urbanization level and blindly pursuing some disturbing trends, such as large-scale urban expansion and serious land wastage, leading to extensive sprawl in built-up areas. However, developed CRs have begun to reflect on the disadvantages of urban sprawl and diffusion. They have begun to seek urban compact development. In fact, this reflects two different stages of urbanization: diffusion and coalescence [30]. "Diffusion" is the early stage of urban development in an isolated enclave formed around a built-up area while "Coalescence" means that when a city has reached a certain stage of development, the spaces or edges between the original urban patches are gradually filled in by new urban land and the integration between urban patches begins. These two processes result in the continuous expansion of urban space $[31,32]$ and have different impacts on the natural environment, resource utilization, and socioeconomic development $[33,34]$. Therefore, it is of great significance to identify the stage of urban expansion at which global urbanization continues at a rapid pace.

Rates and locations of urban development today, as well as the evolution of urban morphologies, are all very different from past trends [35], although many studies have been conducted on the phenomena/processes associated with urban expansion, urban sprawl, and urbanization. We observed that these studies were mostly limited to a single city, region, or country and used diverse data with different time spans, which makes comparison difficult. At present, many studies have focused on urban land-use classification, spatial expansion monitoring, pattern analysis, and model simulation at the mesoscale and microscale, but there has been a lack of studies on global urban spatial patterns and change processes from the macroscale perspective [36]. Therefore, revisiting global spatiotemporal changes in urban expansion for the past 20 years has a new value. Remote sensing is macroscopic, rapid, accurate, dynamic, etc. It can quickly extract urban information through supervised classification, unsupervised classification, index classification, decision analysis, artificial neural networks, and object-oriented information extraction methods. At the same time, it can dynamically monitor urban expansion and scale, as well as obtain the types, quantities, and locations of land-use changes [37, 38]. Moreover, it offers multitemporal and large-scale real-time information for studying change in the spatial expansion of urban built-up areas and has become the main source of information for studying expansion processes. In this paper, we explored three questions with the help of urban land data extracted from two remote sensing image sources. From 1995 to 2015, (1) What were the sources of new urban land in global cities? (2) What were the geographical spatial distributions of the rates of urban expansion? (3) Where was convergence or diffusion-the types of urban expansion around the world-mainly taking place? This study verified that large-scale urban expansion can be mapped with unified data consistent with the definition of urban boundaries and over a unified time frame.

\section{Materials and Methodology}

2.1. Data Sources. Urban areas usually refer to built-up areas where urban facilities and populations are relatively concentrated. Such areas are often replaced by impervious surfaces that can be interpreted by remote sensing images $[30,39]$. The images used in this paper were from the 300 million resolution global land cover data from 1992 to 2015 released by the Climate Change Initiative (CCI), a subsidiary of the European Space Agency, at the WorldCover Conference in March 2017 (http://maps.elie. ucl.ac.be/CCI/viewer/). The advantage of CCI is the public's ability to download land-use data, in which urban cover is encoded as 190. By the end of 2018, according to incomplete statistics, more than 17 academic studies that were published in the top journals on nature communications, environmental remote sensing, and other disciplines used these data to conduct research on the changes in and impacts of land use [40] and earth system models [41, 42]. More publications can be found at https://www.esa-landcover-cci.org/?q=node/184.

The country/region (CR) administrative boundary data mentioned in this paper were provided by both the Global Administrative Areas (GDAM, https://www.gadm.org/) and the Ministry of Natural Resources of the People's Republic of China (http://www.mnr.gov.cn/). There are 226 countries/ regions. We collected GDP data by CR for 1995 and 2015 from the IMF's World Economic Outlook. In addition, we downloaded the latest urban demographics from World Urbanization Prospects 2018 (https://population.un.org/ wup/Download/), which is considered to be the most authoritative data on global urban populations [43], and statistics on global crop production were obtained from the Food and Agriculture Organization of the United Nations.

2.2. Methods. To answer our research questions, we investigated the spatiotemporal changes in global urbanization from 1995 to 2015 according to three dimensions: land-use type, changes in urban coverage, and compactness of urban forms. 
A land-use transition matrix can reflect the dynamic transformation process between types of areas in a certain region at the beginning and the end of a certain period. Urban land was selected as the study focus in this paper. The method extracted new urban pixels from 1995 to 2015 and superimposed them onto the land-use types in 1995 to obtain the proportion of land transferred from other land cover types to urban land. These operations were implemented in ArcGIS10.4.1 software.

The urban growth rate (UGR) was adopted to evaluate the changes in urban coverage over a certain period of time and was the main indicator of changes in urban expansion $[33,44]$. It used the urban land area for a previous period to standardize the average annual growth rate to make UGR comparable and facilitate a horizontal comparison of the intensity or rate of urban land-use growth across different periods.

$$
\mathrm{UGR}=\frac{\mathrm{UA}_{2015}-\mathrm{UA}_{1995}}{\mathrm{UA}_{n 1995}} \times \frac{1}{20} \times 100 \%,
$$

where $\mathrm{UA}_{2015}$ and $\mathrm{UA}_{1995}$ are built-up areas in the studied CRs in 2015 and 1995, respectively.

Urban expansion type is mainly used to describe changes in the spatial morphology of new urban land over a certain period of time. In this paper, the landscape expansion index (LEI) obtained from the literature [45] was used to identify new construction land as marginal, filling, and enclave, and then the respective proportional distributions were calculated to measure the spatial distribution of urban expansion and determine whether the urban morphology had become more aggregated or diffuse [30]. LEI can be calculated by the following equation:

$$
\text { LEI }=\frac{A_{o}}{A_{o}+A_{v}} \times 100,
$$

where $A_{o}$ is the area of intersection between new and original urban patches and $A_{v}$ is the area of intersection between new urban patch buffers and open spaces. If UGP $>50$, the new patches were the filling expansion type. If $0<\mathrm{UGP}<50$, the new patches were the marginal expansion type. If $U G P=0$, the new patches were the enclave expansion type.

Global LEI at the CR level was obtained using the area weighted summation method for the LEIs of all new urban patches:

$$
\mathrm{GLEI}_{i}=\sum_{j=1}^{N} \operatorname{LEI}_{i j} \times \frac{a_{j}}{A_{1995-2015}},
$$

where $\mathrm{GLEI}_{i}$ is the overall landscape expansion index of the $i^{\text {th }} \mathrm{CR}, \mathrm{LEI}_{i}$ and $a_{i}$ are the LEI and area of the $j^{\text {th }}$ newly added urban patch in CR $i, A_{1995-2015}$ is the total amount of new urban area in CR $i$ from 1995 to 2015, and N is the number of new patches. GLEI measured the degree of the aggregation of cities on the national scale from the perspective of the overall landscape. Larger values indicated more aggregate urban morphology; otherwise, it was more diffuse.

\section{Results and Analysis}

The remote sensing images revealed that global urban builtup area was $3.61 \times 10^{5} \mathrm{~km}^{2}$ in 1995 , but by 2015 , it increased to $7.03 \times 10^{5} \mathrm{~km}^{2}$. The UGR over the 20 years was $4.74 \%$. Global LEI was 10.97, which indicated that global urban expansion was still in the typical marginal expansion stage. The bubble distributions of NAUL, UGR, and LEI at the CRs-scale are shown in Figure 1. Six CRs had global NAUL values greater than $1.0 \times 10^{4} \mathrm{~km}^{2}$ (Table 1), four of which were BRICS members. The other two CRs-the United States and Japan-had the largest GDPs in the developed world. The rapid economic development of BRICS CRs in recent years has manifested in the process of urbanization. The major developing CRs have begun to catch up with the major developed CRs in terms of NAUL indicators. The sum of NAUL $\left(1.22 \times 10^{5} \mathrm{~km}^{2}\right)$ values for the five BRICS CRs surpassed the traditional Group 7 value $\left(9.02 \times 10^{4} \mathrm{~km}^{2}\right)$. China alone accounted for $64.02 \%$ of the sum, which was basically the same as its proportion of the GDP (66.8\%) in the five BRICS CRs. The geographical spatial distributions of newly added urban area in all CRs are shown in Figure 2(a).

Figure 3 shows the number of new patches in all CRs. China and the United States together had the most new patches, $2.61 \times 10^{5}$ and $2.15 \times 10^{5}$, respectively. Other CRs with a total number of new patches exceeding 50,000 include Russia $\left(7.94 \times 10^{4}\right)$, Germany $\left(7.58 \times 10^{4}\right)$, and France $\left(5.05 \times 10^{4}\right)$. The CR with the largest average patch area is United Arab Emirates, about $3.55 \mathrm{~km}^{2}$. We found that the average patch areas in the Middle East and Central Asian CRs were generally larger than other regions. For example, Kyrgyzstan, Iraq, Uzbekistan, Turkmenistan, and Azerbaijan belonged to the top $10 \mathrm{CRs}$ in terms of average patch area size.

3.1. Land Sources for NAUL. Statistics on land-use sources for NAUL are shown in Table 2. Obviously, NAUL mainly originated from cultivated land, grassland, and forests. These three types of land use made up about $88.79 \%$ of NAUL land resources.

In general, urban land sources in CRs that are north of the equator were mainly from cultivated land and generally accounted for more than 50\%. In particular, more than $85 \%$ of the NAUL in South and Southeast Asia, as well as Central and Eastern Europe, came from encroaching farmland. For example, in Ukraine (96.53\%), India (which had the largest cultivated area (91.13\%) in Asia), and the world's major rice market exporters-Thailand (95.77\%) and Vietnam (94.91\%) - cultivated land contributed more than $90 \%$ of NAUL. China has a large population and a small per capita cultivated area, but $82.02 \%$ of NAUL came from cultivated land, which poses potential risks to food security [33]. There were 58 CRs that had more than $80 \%$ of NAUL transitioned from cultivated land. These CRs mainly consisted of the aforementioned CRs, as well as developing CRs such as Indonesia, Malaysia, Pakistan, Belarus, Romania, and Egypt. However, Japan, France, and Italy, three major developed CRs (G7 members), as well as other individual developed CRs such as Greece and Poland, were also members of this group, which we can call "Dominated by Cultivated Land." If $80 \%$ was taken as the threshold, then we also identified groups that were "Dominated by Bare Areas," "Dominated 


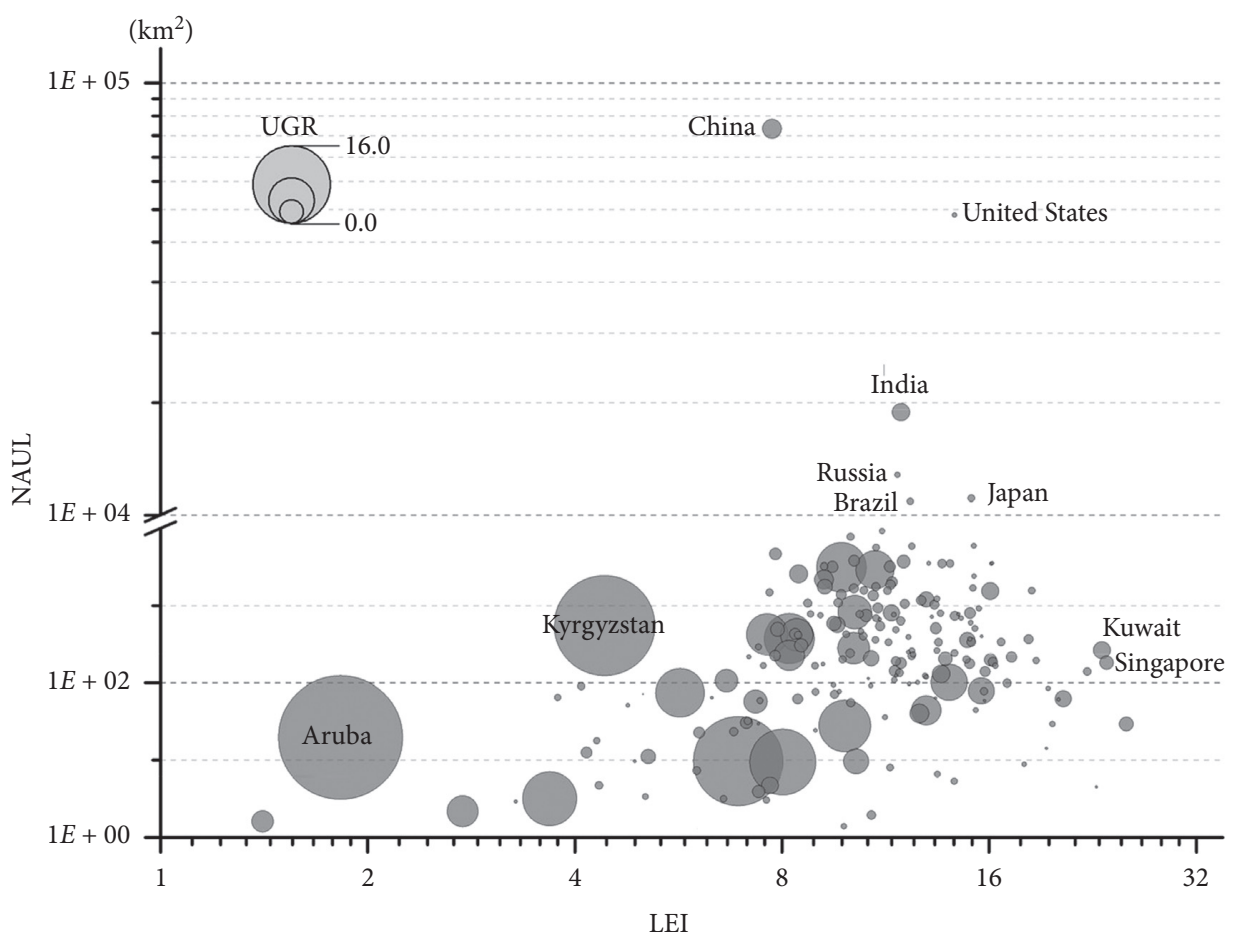

FIgUre 1: Bubble charts of NAUL, UGR, and LEI at the CR scale.

TABLE 1: The six CRs with NAUL values greater than $1.0 \times 10^{4} \mathrm{~km}^{2}$.

\begin{tabular}{lccc}
\hline CR & Urban area by $1995\left(\mathrm{~km}^{2}\right)$ & Urban area by $2015\left(\mathrm{~km}^{2}\right)$ & NAUL $\left(\mathrm{km}^{2}\right)$ \\
\hline China & $3.54 \times 10^{4}$ & $1.14 \times 10^{5}$ & $7.82 \times 10^{4}$ \\
United States & $8.64 \times 10^{4}$ & $1.36 \times 10^{5}$ & $4.94 \times 10^{4}$ \\
India & $8.30 \times 10^{3}$ & $2.56 \times 10^{4}$ & $1.73 \times 10^{4}$ \\
Russia & $1.89 \times 10^{4}$ & $3.13 \times 10^{4}$ & $1.24 \times 10^{4}$ \\
Japan & $1.30 \times 10^{4}$ & $2.40 \times 10^{4}$ & $1.10 \times 10^{4}$ \\
Brazil & $1.38 \times 10^{4}$ & $2.45 \times 10^{4}$ & $1.07 \times 10^{4}$ \\
\hline
\end{tabular}

by Forests," and "Dominated by Grassland." Other single types could not meet the threshold. There were 16 CR types belonging to the "Dominated by Bare Areas" group, which were mostly located in polar and arid areas, e.g., Greenland (98.20\%) and Yemen (90.01\%). "Dominated by Forests" CRs consisted only of French Guiana (89.28\%) and Andorra $(85.71 \%)$ while "Dominated by Grassland" CRs consisted only of Cape Verde (100\%), the Isle of Man (85.22\%), Ireland (83.11\%), Niger (82.78\%), Sudan (82.12\%), and Antigua and Barbuda (81.21\%), but NAUL values for the CRs in all three groups were very small. For CRs with larger areas, the NAUL land sources listed in Table 3 were much more abundant and no one had an absolutely dominant position (more than $80 \%)$. Meanwhile, there were two or three main NAUL types, e.g., agriculture, forest, and grassland in the United States, whereas shrub, forest, and agriculture were the main types in Australia. The spatial distributions for NAUL land sources are shown in Figure 4.

3.2. UGR of NAUL. The spatial distribution of urban expansion rates is shown in Figure 2(b). Over the study period,
Asia had an impressive urbanization rate. We found that in all the five Asian CRs except Kazakhstan, UGR exceeded $20 \%$, which was the highest UGR cluster. In Kyrgyzstan, in particular, the UGR reached 58.91\%, making it the most rapidly growing nation in the world. NAUL increased by about 12.78 times. UGR in China and India reached $11.04 \%$ and $10.41 \%$, respectively, far higher than $2.86 \%$ in the United States and $4.19 \%$ in Japan, which were the most rapidly growing nations among the G7 Western CRs. Considering that China and India had such high NAUL values, their high growth rates were indeed miracles. In fact, not only did both CRs experience rapid urban development, but also their neighbours experienced high UGRs. For example, UGR in Bhutan, Pakistan, and Bangladesh reached 45.12\%, 28.97\%, and $19.69 \%$, respectively.

Due to high urbanization, North America, Oceania, Western Europe, and Northern Europe experienced depressions in their UGRs, which were lower than the global average (4.74\%). Only three CRs in South America were above the average: Ecuador, French Guiana, and Trinidad and Tobago. However, Africa also experienced rapid urbanization. There were $98 \mathrm{CRs}$ or regions -41 of which were 

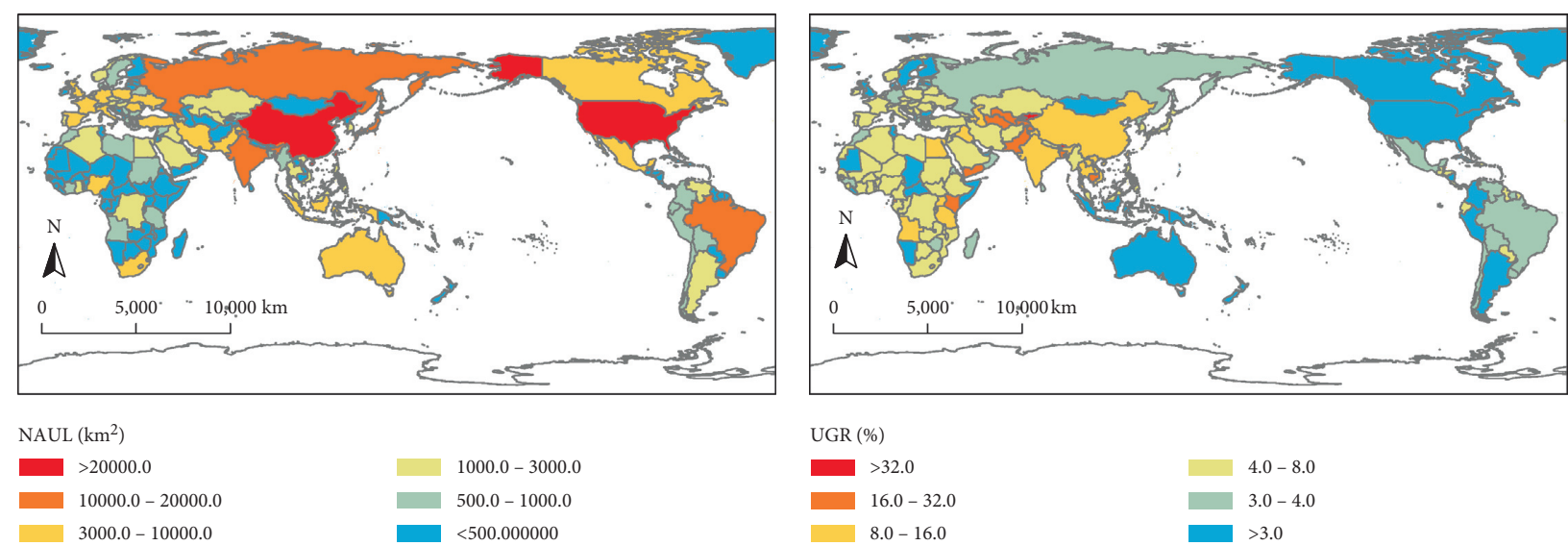

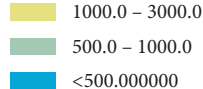

(a)
UGR (\%)

$>32.0$
$16.0-32.0$
$8.0-16.0$
$4.0-8.0$

$3.0-4.0$

(b)
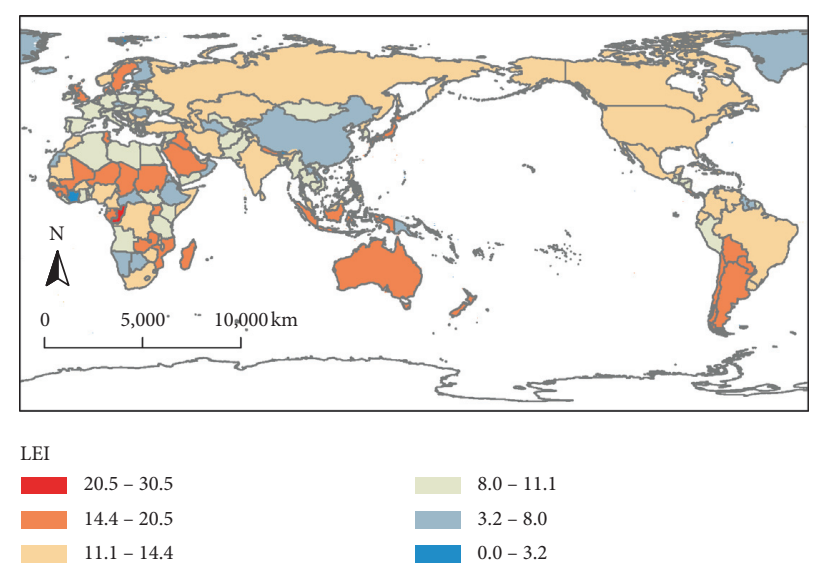

(c)

FIgURE 2: The spatial distributions of urban growth rate, newly added urban size, and compactness at the CR scale.

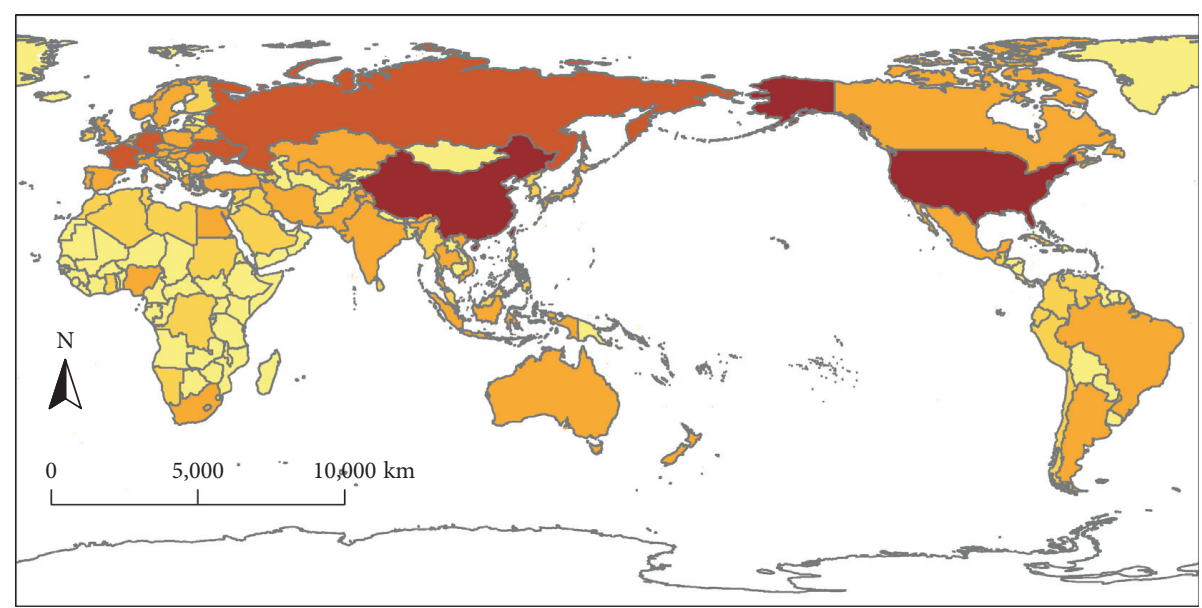

Number of new patches

$>80000$

$1500-5000$

$45000-80000$

$<15000$

$5000-45000$

Figure 3: The number of new patches at the CR scale. 
TABLE 2: Statistics on NAUL land-use sources at the global scale.

\begin{tabular}{lcc}
\hline Original land-use type & Area $\left(\mathrm{km}^{2}\right)$ & Ratio $(\%)$ \\
\hline Agriculture & $2.36 \times 10^{5}$ & 68.93 \\
Grassland & $3.46 \times 10^{4}$ & 10.10 \\
Forest & $3.34 \times 10^{4}$ & 9.76 \\
Bare areas & $1.41 \times 10^{4}$ & 4.12 \\
Shrub land & $1.40 \times 10^{4}$ & 4.10 \\
Sparse vegetation & $5.27 \times 10^{3}$ & 1.53 \\
Water & $2.60 \times 10^{3}$ & 0.76 \\
Wetland & $2.36 \times 10^{3}$ & 0.69 \\
Settlement & $5.27 \times 10^{3}$ & 0.01 \\
\hline
\end{tabular}

TABLE 3: CRs with NAUL from more than one main land-use type.

\begin{tabular}{lcccc}
\hline CR & NAUL $\left(\mathrm{km}^{2}\right)$ & Type 1/ratio (\%) & Type 2/ratio (\%) & Type 3/ratio (\%) \\
\hline United States & $4.94 \times 10^{4}$ & Agriculture/39.26 & Forest/26.96 & Grass/21.01 \\
Brazil & $1.07 \times 10^{4}$ & Agriculture/61.67 & Shrub/18.10 & Forest/14.03 \\
Mexico & $5.87 \times 10^{3}$ & Agriculture/44.34 & Shrub/42.25 & Grass/8.43 \\
England & $3.56 \times 10^{3}$ & Agriculture/53.42 & Grass/37.49 & Forest/5.69 \\
Australia & $3.51 \times 10^{3}$ & Shrub/36.57 & Forest/32.61 & Agriculture/26.15 \\
Korea & $1.68 \times 10^{3}$ & Bare areas/42.77 & Agriculture/27.35 & Grass/7.91 \\
\hline
\end{tabular}

Note. Type 1 refers to the largest source of land use for the NAUL. Similarly, types 2 and 3 refer to the second and third largest land-use sources, respectively.

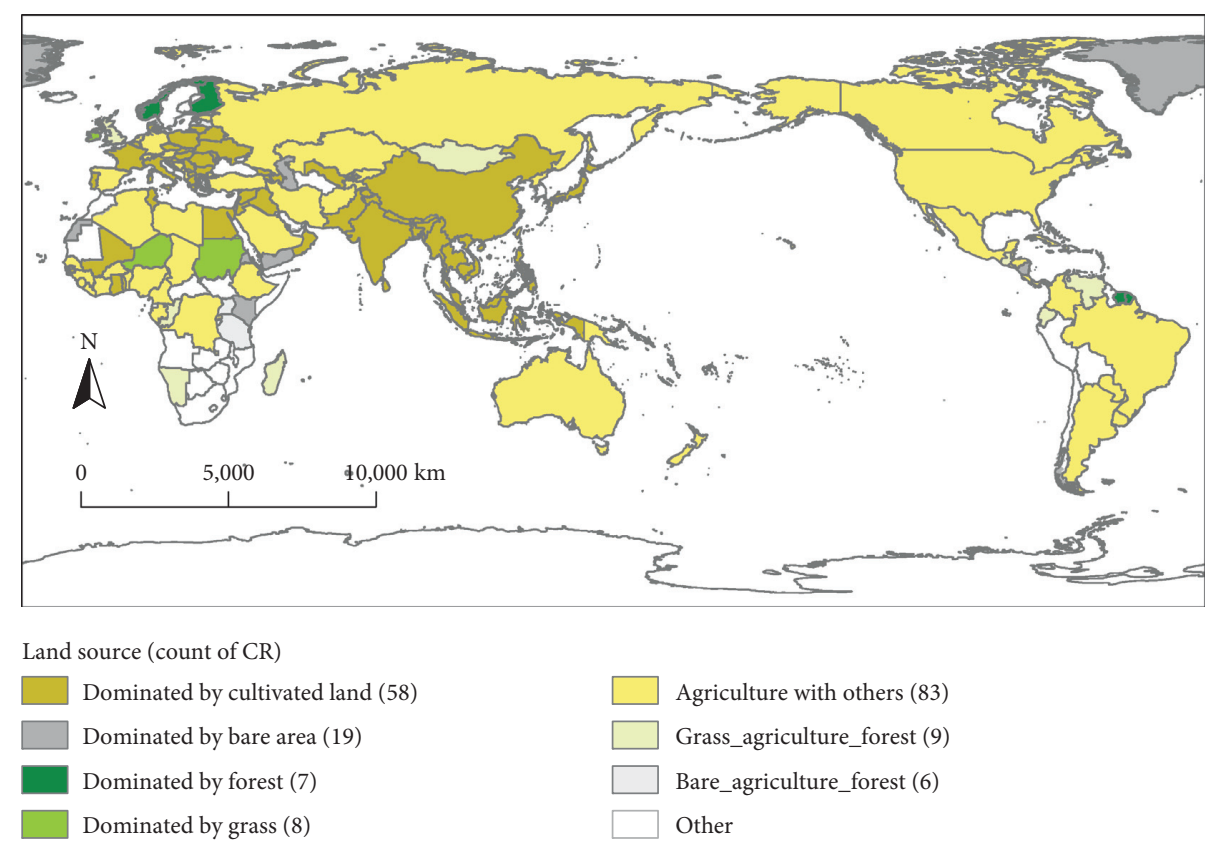

FIgURE 4: The spatial distributions of NAUL land sources at the CR scale.

in Africa-where UGR exceeded the global average (4.74\%). Kenya had the highest UGR at $29.27 \%$, but NAUL was only $373.09 \mathrm{~km}^{2}$. Africa's largest economy, Nigeria, had the highest NAUL, which increased more than $3.72 \times 10^{3} \mathrm{~km}^{2}$, and its UGR was $7.41 \%$. These two indicators were higher than another large CR in Africa-South Africa, whose values were $3.52 \times 10^{3} \mathrm{~km}^{2}$ and $4.93 \%$. With a population of more than 180 million and an urbanization level of only $47.83 \%$
(WUP, 2018), Nigeria is expected to be the next new centre of global urbanization after China and India. Egypt's situation was similar. Although its NAUL $\left(1.76 \times 10^{3} \mathrm{~km}^{2}\right)$ was less than Nigeria and South Africa, its UGR (8.84\%) was higher. Egypt also has a large population (close to 100 million) and still has huge potential for urbanization in the future. If a population of 80 million, a global average UGR $(4.74 \%)$, and an urbanization rate of $50 \%$ are taken as the 
standard, then there are eight CRs-called the Emerging Urban Growth G8-whose future global urban expansions will constitute the global majority.

3.3. Compactness of NAUL. The spatial distribution of national LEI is shown in Figure 2(c). We did not identify CRs with LEIs greater than 50, i.e., smart and compact measures of population expansion did not appear on the national scale. The top five LEI CRs were Gibraltar, Monaco, Singapore, Kuwait, and Hong Kong, with respective values of $30.54,30.15,23.70,23.33$, and 20.51. Overall, these CRs had very high urbanization rates, relatively high levels of urban development, and scarce land resources suitable for urban expansion. Therefore, it was difficult to convert land around original cities. Urban spatial development should fill gaps within original cities or empty spaces between existing patches. As a result, urban forms have become more compact.

Oceania had the highest average LEI at 15.71, whereas Asia had the lowest at 8.98. The LEIs of the two major CRs in Oceania-Australia and New Zealand-were 16.10 and 15.18 , respectively. With rapid urbanization in Asia represented by China and India, the expansion of cities mainly occurred through cultivated land conversion around original cities, resulting in an extensive morphological trend. China's LEI was only 7.73, which was the lowest of the world's major CRs (G20 CRs) and indicated the most obvious trend of diffuse urban expansion. The concept of the "Compact City" was introduced in Europe with an LEI of 10.42 , which was not as high as those of other continents. The top three CRs were the United Kingdom, the Netherlands, and Denmark with respective LEIs of 16.16, 15.17, and 15.04. In the United States, the birthplace of "Smart Growth," LEI was 14.24, which was higher than the average level of North America (11.93). Interestingly, the average LEI of African CRs was 12.36, second only to Oceania. Moreover, Africa was home to many CRs that were representative regions of urban compact development with LEI greater than 18. South America's overall LEI was 12.24 and its representative CR, Brazil, had a value of 12.29. Though Brazil had the world's sixth highest NAUL, the slums have been a typical problem for urbanization. They have, to some extent, increased the connectivity between new urban patches and improved compactness. Therefore, compared to China, India, and Russia, which also had high NAUL values, Brazil had the highest LEI.

China had the most outlying patches, with $1.89 \times 10^{5}$. The United States had the most infilling patches $\left(4.91 \times 10^{4}\right)$ and edge patches $\left(8.88 \times 10^{4}\right)$, and the corresponding numbers in China were $1.12 \times 10^{4}$ and $6.08 \times 10^{4}$, which showed that the United States was more compact than the increase in Chinese cities. We also found that the Central Asia region had the highest average patch area of all three types (Figure 5). For example, the United Arab Emirates had the largest average area of outlying patches $\left(1.47 \mathrm{~km}^{2}\right)$ and edge patches $\left(17.82 \mathrm{~km}^{2}\right)$, and Kyrgyzstan's infilling patches were the largest $\left(5.12 \mathrm{~km}^{2}\right)$.

\section{Discussion}

4.1. Has Urban Expansion Threatened Global Food Security? Urban expansion's threat to food security has been widely reported by scholars around the world [46, 47]. The most significant evidence is the large amount of cultivated land being used to provide new land for urban development. Global urbanization caused a $2.36 \times 10^{5} \mathrm{~km}^{2}$ loss of cultivated land, which contributed to more than $50 \%$ of NAUL in most CRs. However, there has been no global loss of grain production, according to FAO Crops statistics. We compared the total production of five major staple food crops-barley, potatoes, rice, soybeans, and wheat-for 1995 and 2015. The results showed a $43.04 \%$ increase from $1.58 \times$ $10^{9}$ to $2.26 \times 10^{9}$ tonnes and an $11.27 \%$ increase in per capita crops (PCC) from 0.275 to 0.306 tonnes. The correlation coefficients between PCC change and the ratio of agricultural land to all land sources for NAUL (ArgR), as well as UGR, were measured by the Pearson coefficient, with respective results of 0.125 and -0.00215 , which indicated that global PCC changes had weak positive correlations or no correlation with $\operatorname{ArgR}$ (i.e., urbanization did not seem to affect food security and CRs with a higher proportion of cultivated land occupied by urban expansion were actually more likely to increase PCC). These results may indicate that, with the improvement of agricultural science and technology, the increase in crop yields largely compensated for the decrease in cultivated land. However, in different regions, we found weak correlations between PCC variation and ArgR in all continents with a correlation coefficient of 0.4215 in the Americas. Correlations between UGR and the change in PCC exhibited large regional differences. In addition to Europe and Asia, there were no correlations for other continents, but in Europe, UGR and the change in PCC had a weak negative correlation $(-0.13738)$, which meant that rapid urbanization may have contributed to the decline in PCC. No similar results were found for other continents. In fact, of the 31 European CRs for which statistics are available, 17 CRs had declining CPP. Poland, in particular, had the largest reduction in PCC per capita in the world with a reduction of more than 0.43 . In Asia, the correlation coefficient was 0.19 , indicating a weak positive correlation and that the urbanization process could promote the increase of CPP. In fact, in Asian CRs, especially China and India, the total grain output and PCC increased steadily during rapid urbanization. Research shows that chemical fertilizers play a significant role in improving crop yields [48-50].

\subsection{Have Urban Land Expansion Rates Exceeded Urban} Population Growth Rates? The global urban population increased from 1995 to 2015 by more than $54.38 \%$, from 2.582 billion to 3.986 billion. This was lower than the $94.74 \%$ increase in urban land and suggests that urban growth is becoming more expansive than compact. There were at least 156 CRs (excluding those that lacked demographic data) 


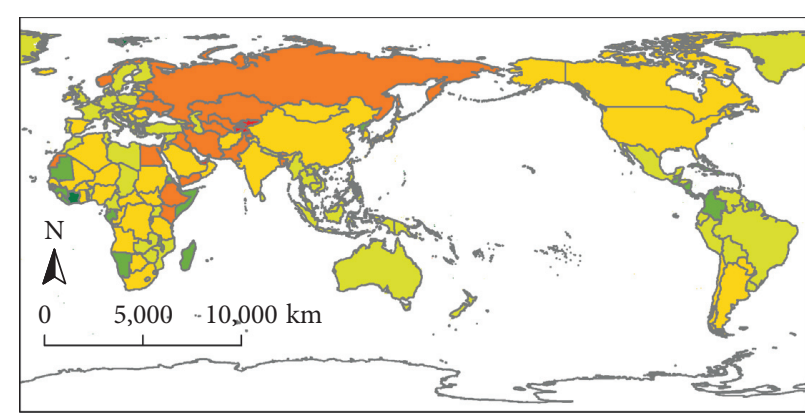

Average patch area Outlying $\left(\mathrm{km}^{2}\right)$

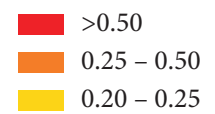

$0.15-0.20$

$<0.10$

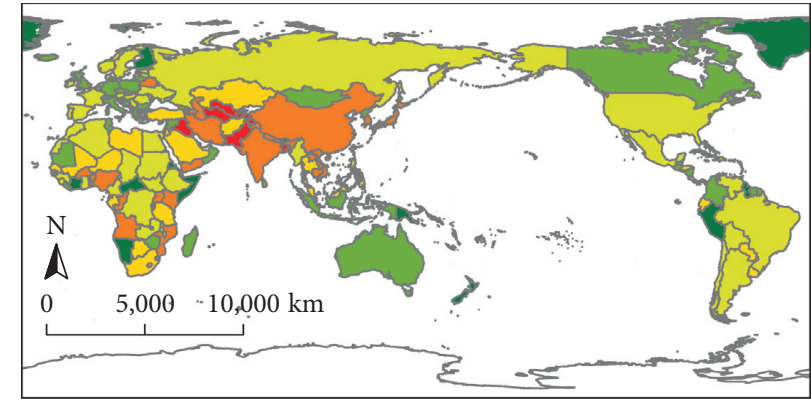

Average patch area

Edge $\left(\mathrm{km}^{2}\right)$

$<2.00$
$1.00-2.00$
$0.75-1.00$

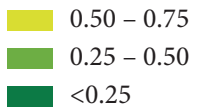

(b)

(a)

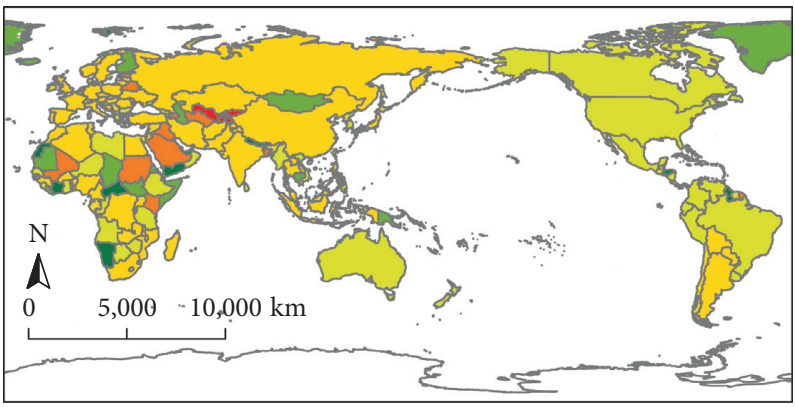

Average patch area Infilling $\left(\mathrm{km}^{2}\right)$

$<1.00$
$0.50-1.00$
$0.25-0.50$

$0.15-0.25$
$0.10-0.15$
$<0.10$

(c)

Figure 5: Average patch area of each urban growth type at the CR scale.

whose urban land expansion rates exceeded their urban population growth rates. The answer to "Have urban land expansion rates exceeded urban population growth rates?" is yes. China, Central Asia, South Asia, Southeast Asia, and Eastern Europe are agglomeration areas that formed a large gap. For example, the mismatch between land urbanization and population urbanization resulting in the trend of the diffusion of urban morphology in China has been widely reported [30]. In order to curb this trend, the Chinese government has introduced a "new urbanization" strategy of promoting people-oriented urbanization rather than simply urban area expansion. On the other hand, these regions are also the most densely populated regions in the world and have a large number of people to feed because of limited cultivated land resources. Because the loss of cultivated land due to urban expansion threatens food security, adequate attention should be given to its loss. African CRs also have experienced a rapid increase in urban areas in the past 20 years, but the urban populations have increased even more rapidly. Africa is the only continent where the urban population is growing more rapidly than urban areas. Only $44 \mathrm{CRs}$ in the world belong to this category and more than 27 are located in Africa, accounting for more than $60 \%$ and indicating that African cities are growing but actually becoming more crowded. In the Americas, Europe, and Oceania, the rates of land urbanization and population urbanization are basically being kept in balance, which may be related to the fact that these continents already had very high urbanization rates in 1995, the start of the study period. For example, urbanization rates in North America, South America, and Oceania were 77.3\%, 77\%, and 85\%, respectively, in 1995. A regression analysis of urban land expansion and population urbanization rates in 1995 also showed that population urbanization rates had significant inhibitory effects on urban land expansion rates (coefficient is -1.87 at a significance of 0.001).

\subsection{Is Higher Economic Development Accompanied by Greater} Compactness? "Compact cities" are an urban planning trend from Western developed CRs with the goal of making full use of existing urban spaces, improving mixed land use, and promoting the enrichment and improvement of urban infrastructure [30, 51]. As representatives of high-income CRs 
and pioneers of "compact cities," do Western developed CRs pay more attention to compactness ratios in urban construction? From all the global CRs correlation tests, we found that there was no correlation between the level of economic development represented by per capita GDP and the compactness ratio. Wealthy CRs, such as the United States, Canada, Australia, and Japan, had high LEI levels. We can found that middle-income CRs, such as Indonesia, Iraq, and Turkey, as well as low-income CRs, such as Mali, Niger, and Sudan, also had high LEI levels. However, the NAUL cardinalities of some middle-income CRs were too small, so we speculated that they had high LEIs. Urban expansion does not need to occupy a large amount of land outside original urban built-up areas, and most urban growth demands can be satisfied by filling in the interiors of cities or gaps in original urban patches [30]. Through further analysis, we found that when the CRs with UAUAs less than $500 \mathrm{~km}^{2}$ were removed, the correlation coefficient was 0.14 . If CRs with UAUAs less than $1000 \mathrm{~km}^{2}$ were removed, the correlation value was 0.40 and the correlation was significantly higher, indicating that for regions with significant UAUA growth $\left(>1000 \mathrm{~km}^{2}\right)$, the level of economic development played a positive role in improving urban compact development. For example, the average LEI of Western G7 CRs was 17.09, far exceeding the 9.32 of the BRICS CRs. At the patch scale, we also found that economic density (reflected by night light brightness) in infilled patches was 1.19 and 1.42 times the values for edge and outlying patches, respectively, indicating high economic density was conducive to compact patch development.

\section{Conclusions}

With the help of global land cover data and GIS analysis, this study adopted a unified data source, the same analysis method, and the same time span to trace the global urban expansion process from 1995 to 2015. Moreover, this study overcame the traditional research limitation of focusing on single cities or CRs and provided a convenient method for tracking global urbanization expansion and comparing international cases.

We found that agriculture, grassland, and forest contributed to almost $90 \%$ of global urban land expansion. Agriculture alone contributed $68.93 \%$. However, the total grain output of the world and per capita ratios have been reduced by the loss of cultivated land. On the contrary, higher urban expansion due to the conversion of cultivated land led to higher increases in PCC. Therefore, we believe that the hypothesis that urban expansion poses a threat to global food security is not valid. In terms of the NAUL index, the major developing CRs in the world have begun to catch up with the major developed CRs. China and India led the global urbanization process during the study period, and new urban land area distributions ranked first and third, respectively, in the world. These rankings were indeed a miracle. The next eight CRs to create new miracles may include India, Pakistan, Nigeria, Bangladesh, the Philippines, Ethiopia, Egypt, and Vietnam, which have been defined as the "Emerging Urban Growth G8" because of their large population sizes, population urbanization rates of less than $50 \%$, and rapid urban expansion. We also noted that although Africa and Asia are undergoing rapid urbanization, land urbanization in Asia was significantly more rapid than population urbanization, whereas Africa was the only continent where the urban population grew more rapidly than urban areas. These results suggested that more crowded cities may be a problem for future urbanization in Africa, whereas Asia may need to focus on low-density sprawl. Although Western developed CRs did not expand as rapidly as developing CRs, they emphasized compact urban development and maintained harmony with the rate of population urbanization.

Unfortunately, because of the limitations of the data and the length of this paper, much of the paper only described spatiotemporal changes in urban land around the world. We rarely investigated the causes of these changes, i.e., we "presented the existence of the phenomenon, but did not analyze the reasons for it." Therefore, these causes will be the focus of future research to explore the driving factors behind urban evolution in different CRs.

\section{Data Availability}

The data used to support the findings of this study are available from the corresponding author upon request.

\section{Conflicts of Interest}

The authors declare no conflicts of interest.

\section{Authors' Contributions}

Yang Zhang and Yingxue Rao performed data analysis and wrote the manuscript. Huiying Wang assisted in manuscript editing and article review. Peng Xie designed the study and assisted in data analysis. Qingsong He provided the initial data and instruments from his study.

\section{Acknowledgments}

This research was financially supported by the National Social Science Foundation (no. 19BJY059), the Project of Reform and Innovation of Academic Degree and Graduate Education in UIBE (no. 19400), the Fundamental Research Funds for the Capital University of Economics and Business (no. QNTD202009), and Open Research Fund Program of Key Laboratory of Digital Mapping and Land Information Application Engineering, NASG (no. ZRZYBWD201908).

\section{References}

[1] Y. Zhang, X. Liu, G. Chen, and G. Hu, "Simulation of urban expansion based on cellular automata and maximum entropy model," Science China Earth Sciences, vol. 63, no. 5, pp. 701-712, 2020.

[2] X. Liu, F. Pei, Y. Wen et al., "Global urban expansion offsets climate-driven increases in terrestrial net primary productivity," Nature Communications, vol. 10, no. 1, p. 5558, 2019.

[3] B.-J. He, L. Ding, and D. Prasad, "Enhancing urban ventilation performance through the development of precinct 
ventilation zones: a case study based on the Greater Sydney, Australia," Sustainable Cities and Society, vol. 47, Article ID 101472, 2019.

[4] Z. Qiao, X. Xu, M. Zhao, F. Wang, and L. Liu, “The application of a binary division procedure to the classification of forest subcategories using MODIS time-series data during 20002010 in China," International Journal of Remote Sensing, vol. 37, no. 10, pp. 2433-2450, 2016.

[5] Z.-Q. Zhao, B.-J. He, L.-G. Li, H.-B. Wang, and A. Darko, "Profile and concentric zonal analysis of relationships between land use/land cover and land surface temperature: case study of Shenyang, China," Energy and Buildings, vol. 155, pp. 282-295, 2017.

[6] B. L. Turner, E. F. Lambin, and A. Reenberg, "The emergence of land change science for global environmental change and sustainability," Proceedings of the National Academy of Sciences, vol. 104, no. 52, pp. 20666-20671, 2007.

[7] L. Jiang, B. Xue, Z. Ma, L. Yu, B. Huang, and X. Chen, "A lifecycle based co-benefits analysis of biomass pellet production in China," Renewable Energy, vol. 154, pp. 445-452, 2020.

[8] Z. Qiao, L. Liu, Y. Qin, X. Xu, B. Wang, and Z. Liu, "The impact of urban renewal on land surface temperature changes: a case study in the main city of guangzhou, China," Remote Sensing, vol. 12, no. 5, p. 794, 2020.

[9] T. Bakirtas and A. G. Akpolat, "The relationship between energy consumption, urbanization, and economic growth in new emerging-market countries," Energy, vol. 147, pp. 110121, 2018.

[10] X. Li, J. Song, T. Lin et al., "Urbanization and health in China, thinking at the national, local and individual levels," Environmental Health, vol. 15, no. 1, p. 32, 2016.

[11] C. Qian, Y. Deyong, G. Matei, W. Jianguo, and W. Wei, "Impacts of future urban expansion on summer climate and heat-related human health in eastern China," Environment International, vol. 112, pp. 134-146, 2018.

[12] D. Mao, Z. Wang, J. Wu et al., "China's wetlands loss to urban expansion," Land Degradation \& Development, vol. 29, no. 8, pp. 2644-2657, 2018.

[13] V. Ruiz Rincón, J. Martínez-Alier, and S. Mingorria, "Environmental conflicts related to urban expansion involving agrarian communities in Central Mexico," Sustainability, vol. 11, no. 23, p. 6545, 2019.

[14] A. Guo, J. Yang, X. Xiao et al., "Influences of urban spatial form on urban heat island effects at the community level in China," Sustainable Cities and Society, vol. 53, Article ID 101972, 2020.

[15] Z. Qiao, C. Wu, D. Zhao et al., "Determining the boundary and probability of surface urban heat island footprint based on a logistic model," Remote Sensing, vol. 11, no. 11, p. 1368, 2019.

[16] E. S. Krayenhoff, M. Moustaoui, A. M. Broadbent, V. Gupta, and M. Georgescu, "Diurnal interaction between urban expansion, climate change and adaptation in US cities," Nature Climate Change, vol. 8, no. 12, pp. 1097-1103, 2018.

[17] M. Garschagen and P. Romero-Lankao, "Exploring the relationships between urbanization trends and climate change vulnerability," Climatic Change, vol. 133, no. 1, pp. 37-52, 2015.

[18] B.-J. He, Z.-Q. Zhao, L.-D. Shen, H.-B. Wang, and L.-G. Li, "An approach to examining performances of cool/hot sources in mitigating/enhancing land surface temperature under different temperature backgrounds based on landsat 8 image," Sustainable Cities and Society, vol. 44, pp. 416-427, 2019.
[19] J. Yang, S. Jin, X. Xiao et al., "Local climate zone ventilation and urban land surface temperatures: towards a performancebased and wind-sensitive planning proposal in megacities," Sustainable Cities and Society, vol. 47, Article ID 101487, 2019.

[20] J. Yang, J. Sun, Q. Ge, and X. Li, “Assessing the impacts of urbanization-associated green space on urban land surface temperature: a case study of Dalian, China," Urban Forestry \& Urban Greening, vol. 22, pp. 1-10, 2017.

[21] Y. Wu, S. Li, and S. Yu, "Monitoring urban expansion and its effects on land use and land cover changes in Guangzhou city, China," Environmental Monitoring and Assessment, vol. 188, no. 1, p. 54, 2016.

[22] W. Song, B. C. Pijanowski, and A. Tayyebi, "Urban expansion and its consumption of high-quality farmland in Beijing, China," Ecological Indicators, vol. 54, pp. 60-70, 2015.

[23] B. d. A. Christopher, R. Femke, B. Giovanni et al., "Future urban land expansion and implications for global croplands," Proceedings of the National Academy of Sciences of the United States of America, vol. 114, no. 34, pp. 8939-8944, 2017.

[24] W. Zhou, S. Zhang, W. Yu, J. Wang, and W. Wang, "Effects of urban expansion on forest loss and fragmentation in six megaregions, China," Remote Sensing, vol. 9, no. 10, p. 991, 2017.

[25] Y. Zhang, W. Shen, M. Li, and Y. Lv, "Assessing spatiotemporal changes in forest cover and fragmentation under urban expansion in Nanjing, eastern China, from long-term Landsat observations (1987-2017)," Applied Geography, vol. 117, Article ID 102190, 2020.

[26] R. Glaser, P. Haberzettl, and R. P. D. Walsh, "Land reclamation in Singapore, Hong Kong and Macau," GeoJournal, vol. 24, no. 4, pp. 365-373, 1991.

[27] K. Cheng, J. Wang, D. Jaahanaa, and X. Han, "Urban expansion and driving force analysis of Ulaanbaatar in Mongolia in recent thirty years," Remote Sensing Technology and Application, vol. 34, no. 1, pp. 90-100, 2019.

[28] H. van Ginkel, "Urban future," Nature, vol. 456, no. 1, pp. 32-33, 2008.

[29] S. K. C and G. H. L. R. Burak, "Global forecasts of urban expansion to 2030 and direct impacts on biodiversity and carbon pools," Proceedings of the National Academy of Sciences of the United States of America, vol. 109, no. 40, pp. 16083-16088, 2012.

[30] Q. He, Y. Song, Y. Liu, and C. Yin, “Diffusion or coalescence? Urban growth pattern and change in 363 Chinese cities from 1995 to 2015," Sustainable Cities and Society, vol. 35, pp. 729-739, 2017.

[31] Q. He, W. He, Y. Song, J. Wu, C. Yin, and Y. Mou, "The impact of urban growth patterns on urban vitality in newly built-up areas based on an association rules analysis using geographical "big data"” Land Use Policy, vol. 78, pp. 726-738, 2018.

[32] Y. Liu, Q. He, R. Tan, Y. Liu, and C. Yin, "Modeling different urban growth patterns based on the evolution of urban form: a case study from Huangpi, Central China," Applied Geography, vol. 66, pp. 109-118, 2016.

[33] K. Zhou, Y. Liu, R. Tan, and Y. Song, "Urban dynamics, landscape ecological security, and policy implications: a case study from the Wuhan area of central China," Cities, vol. 41, pp. 141-153, 2014.

[34] Y. Mou, Y. Song, Q. Xu, Q. He, and A. Hu, "Influence of urban-growth pattern on air quality in China: a study of 338 cities," International Journal of Environmental Research and Public Health, vol. 15, no. 9, p. 1805, 2018. 
[35] K. C. Seto, R. Sánchez-Rodríguez, and M. Fragkias, “The new geography of contemporary urbanization and the environment," Annual Review of Environment and Resources, vol. 35, no. 1, pp. 167-194, 2010.

[36] G. Chen, X. Li, X. Liu et al., "Global projections of future urban land expansion under shared socioeconomic pathways," Nature Communications, vol. 11, no. 1, p. 537, 2020.

[37] X.-P. Song, J. O. Sexton, C. Huang, S. Channan, and J. R. Townshend, "Characterizing the magnitude, timing and duration of urban growth from time series of Landsat-based estimates of impervious cover," Remote Sensing of Environment, vol. 175, pp. 1-13, 2016.

[38] J. Yang, Y. Wang, X. Xiao et al., "Spatial differentiation of urban wind and thermal environment in different grid sizes," Urban Climate, vol. 28, Article ID 100458, 2019.

[39] L. Jiao, L. Mao, and Y. Liu, "Multi-order landscape expansion index: characterizing urban expansion dynamics," Landscape and Urban Planning, vol. 137, pp. 30-39, 2015.

[40] G. Duveiller, J. Hooker, and A. Cescatti, "The mark of vegetation change on Earth's surface energy balance," Nature Communications, vol. 9, no. 1, p. 679, 2018.

[41] B. Poulter, N. MacBean, A. Hartley et al., "Plant functional type classification for earth system models: results from the European space agency's land cover climate change initiative," Geoscientific Model Development, vol. 8, no. 7, pp. 2315-2328, 2015.

[42] A. J. Hartley, N. MacBean, G. Georgievski, and S. Bontemps, "Uncertainty in plant functional type distributions and its impact on land surface models," Remote Sensing of Environment, vol. 203, pp. 71-89, 2017.

[43] R. Meredith, R. Femke, and S. K. C, "Spatializing 6,000 years of global urbanization from 3700 BC to AD 2000," Scientific Data, vol. 3, Article ID 160034, 2016.

[44] X. Xu and X. Min, "Quantifying spatiotemporal patterns of urban expansion in China using remote sensing data," Cities, vol. 35, pp. 104-113, 2013.

[45] X. Liu, X. Li, Y. Chen, Z. Tan, S. Li, and B. Ai, "A new landscape index for quantifying urban expansion using multitemporal remotely sensed data," Landscape Ecology, vol. 25, no. 5, pp. 671-682, 2010.

[46] C. He, Z. Liu, M. Xu, Q. Ma, and Y. Dou, "Urban expansion brought stress to food security in China: evidence from decreased cropland net primary productivity," Science of the Total Environment, vol. 576, pp. 660-670, 2017.

[47] B. Pandey and K. C. Seto, "Urbanization and agricultural land loss in India: comparing satellite estimates with census data," Journal of Environmental Management, vol. 148, pp. 53-66, 2015.

[48] M. Hossain and V. P. Singh, "Fertilizer use in Asian agriculture: implications for sustaining food security and the environment," Nutrient Cycling in Agroecosystems, vol. 57, no. 2, pp. 155-169, 2000.

[49] Y. Li, W. Zhang, L. Ma et al., "An analysis of China’s fertilizer policies: impacts on the industry, food security, and the environment," Journal of Environmental Quality, vol. 42, no. 4, pp. 972-981, 2013.

[50] P. Simha, C. Lalander, B. Vinnerås, and M. Ganesapillai, "Farmer attitudes and perceptions to the re-use of fertiliser products from resource-oriented sanitation systems - the case of Vellore, South India," Science of The Total Environment, vol. 582, pp. 885-896, 2017.

[51] M. R. Shirazi, "Compact urban form: neighbouring and social activity,” Sustainability, vol. 12, no. 5, p. 1987, 2020. 